\title{
Design of Flat Vaults with Topological Interlocking Solids
}

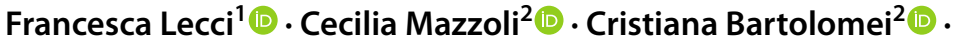 Riccardo Gulli ${ }^{2}$}

Accepted: 25 November 2020 / Published online: 19 December 2020

(c) The Author(s) 2020

\begin{abstract}
This paper investigates the principles that regulate complex stereotomic constructions as a starting point for the design of a new two-dimensional floor structure based on the principles of TIM (Topological Interlocking Materials). These interlocking systems use an assembly of identical Platonic solids which, due to the mutual bearing between adjacent units and the presence of a global peripheral constraint, lock together to form pure geometric shapes. This type of structure offers several advantages such as a high energy dissipation capacity and tolerance towards localised failure, which has made it a popular research topic over the last 30 years. The current research project includes a case study of an assembly of interlocking cubes to create a "flat vault". The resulting vault design features a striking appearance and its geometry may be manipulated to achieve different twodimensional solutions, provided certain geometric conditions necessary for the stability of the system are followed.
\end{abstract}

Keywords Stereotomy · Flat vault · Topological Interlocking Materials (TIM) · Interlocking Platonic solids $\cdot$ Floor surfaces

Cristiana Bartolomei

cristiana.bartolomei@unibo.it

Francesca Lecci

francesca.lecci@arup.com

Cecilia Mazzoli

cecilia.mazzoli2@unibo.it

Riccardo Gulli

riccardo.gulli@unibo.it

1 Arup, 8-13 Fitzroy St, Bloomsbury, London W1T 4BQ, UK

2 DA - Department of Architecture, University of Bologna, Viale del Risorgimento 2, Bologna, Italy 


\section{Introduction}

This paper aims to investigate the geometric and structural properties of flat vaults composed of topological interlocking cubes. Topological Interlocking Systems (TIM) involve the organisation of modular elements to create a structure held together by a peripheral constraint or ring beam: in its simplest form, this can be a structural frame surrounding a vault, which is formed by elements mutually supporting each other, hence each module is locked in position by purely geometric constraints.

This type of structure has a number of advantages that have made TIM a widely researched topic both in the architectural and structural engineering fields over the past three decades. In order to provide an adequate understanding of the properties of this type of architectural system, the present paper includes an analysis of the historic forms of flat vaults, from the fifteenth century onwards, followed by the description of the design, and virtual and physical modelling techniques for a case study of flat vault composed of topological interlocking cubes.

\section{Historical Precedents}

\section{Flat Vaults}

The stereotomic system known as voute plate (flat vault)... can be rarely found in its built form.... The underlying historical problem concerns... building a vault made of voussoirs and with a rise equal to zero or with an infinite radius.... The static principle at the basis of this system requires that the load path in the structure changes its direction from vertical to horizontal, through an adequate clamping of the stone blocks to ensure the compression of the whole vault system (Fallacara 2007: 116-118, our trans.).

Common flat vaults can be geometrically generated as a result of either the longitudinal extrusion of a jack arch, which leads to a flat vault with straight courses, constrained on two sides, similar to a barrel vault, or the revolution of a jack arch around its centre to generate a vault with circular courses and restrained along its whole perimeter (Fig. 1).

Vaults with low rises were observed mainly towards the end of the Gothic period (Noël 1994). An interesting development of this type of construction is noted especially in Spain, starting in the fifteenth century. Some examples can be found in the Casas Consistoriales in Seville (1527), which feature vaults with an orthogonal grid of ribs, in the crypt of the San Sebastian church in Villacastin (1529) and in the royal chapel of the Cathedral in Seville (1550).

With reference to flat vaults without reinforcing ribs, an important precedent can be found in the Escorial, near Madrid, which features the first known case of a flat vault in Spain. The geometry of the vault of the Escorial was generated through the revolution of a jack arch around its keystone, hence creating circular 

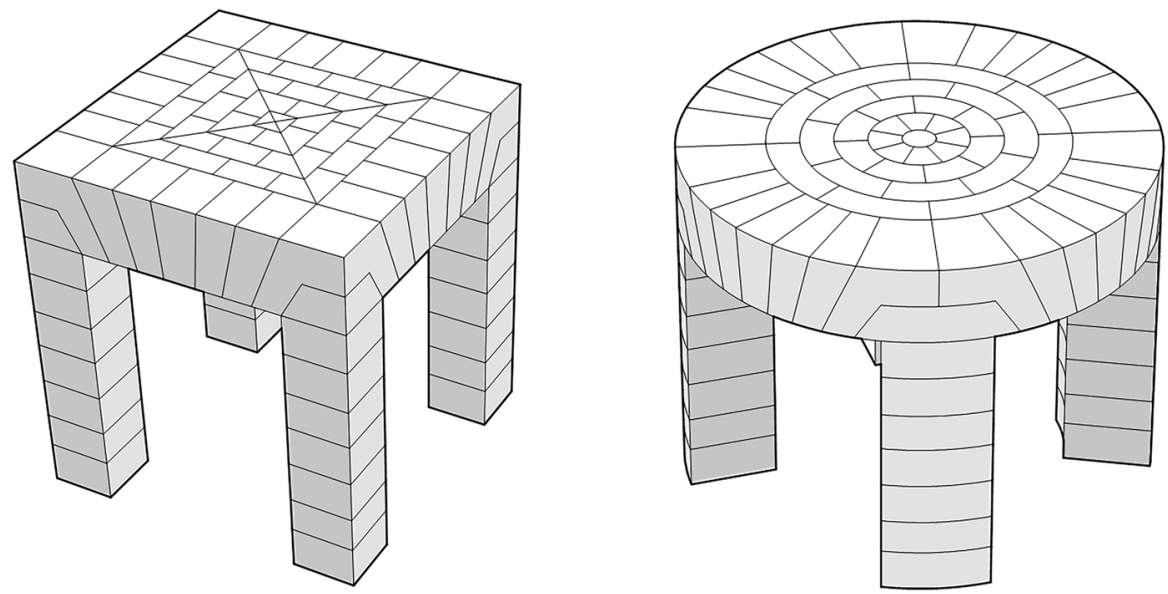

Fig. 1 Examples of flat vaults with concentric courses. Left: flat vault with quadrilateral plan; right: flat vault with circular plan. Image: Francesca Lecci

courses of voussoirs (López Mozo 2003). The vault is supported by four peripheral arches, has a $7.80 \mathrm{~m} \times 7.80 \mathrm{~m}$ quadrilateral plan and a cross-section depth of $0.28 \mathrm{~m}$ (corresponding to the unit of the Castilian foot). The central surface of the soffit traces out a shallow dome in profile (Fig. 2).

At the end of the seventeenth century, another exceptional flat vault was invented by the French engineer Joseph Abeille. The modular components of the vault are polyhedra of equal dimensions, having a square base, an upper rectangular surface and four sloped surfaces on the sides, which are used to support the elements. Abeille's structure is conceived as a dry masonry system: the stone modules are arranged alternatingly so that each stone piece is supported by two adjacent pieces, without the use of any type of joinery or mortar (Rabasa Díaz 1998). The resulting vault is able to redirect the vertical load horizontally towards the walls on the perimeter and features a checkerboard pattern on its intrados and pyramidal voids on its extrados (Fig. 3).

In the following years, Abeille's structure (Fig. 4a) was at the centre of a theoretical speculation on possible design solutions to create a flat, walkable

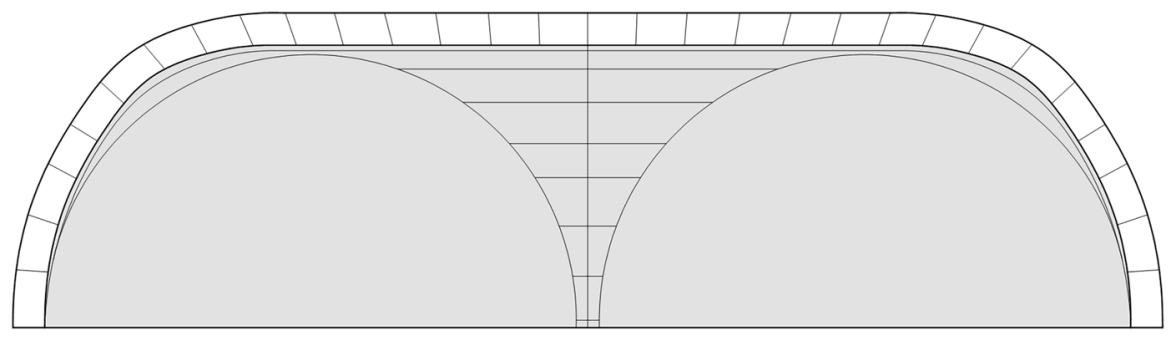

Fig. 2 Speculative sketch showing the diagonal vertical section of the flat vault of the Escorial Monastery. Image: Authors, after López Mozo (2003) 


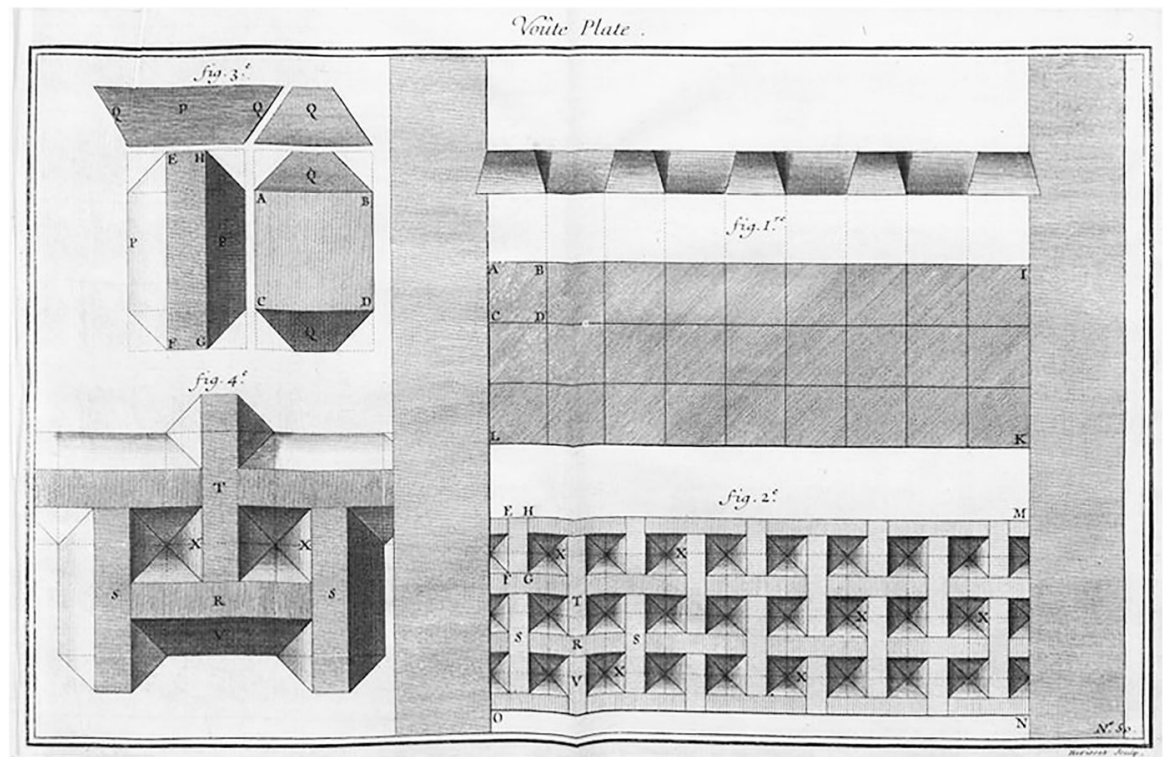

Fig. 3 Joseph Abeille's "Voûte plate": drawings of polyhedral stone modules and assembled system of a flat vault, invented in 1699. Image: Gallon (1735)
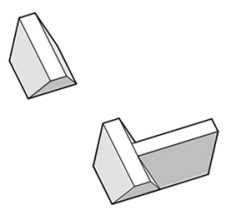

(a)
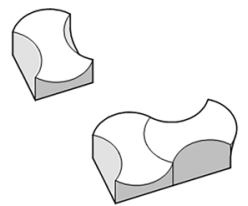

(b)
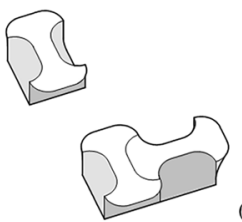

(c)
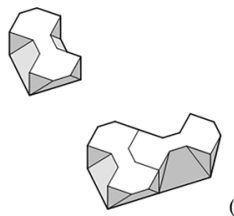

(d)

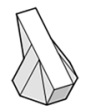

(f)

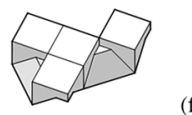

(e)
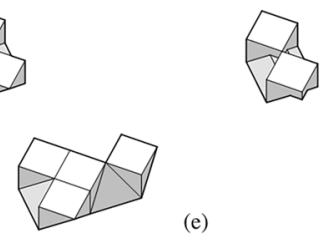

Fig. 4 Alternative geometric modules for Abeille's vault: a Abeille's module; b Truchet's module; c-h Frézier's modules. Images: Francesca Lecci

extrados for the vault. The theorist that started this debate was the mathematician Jean Truchet, who explored an alternative geometric shape for the repeating module of Abeille's vault in order to fill the voids on its upper surface. However, the module designed by Truchet (Fig. 4b) appears to be rather complex, as it entails the creation of ruled surfaces.

In the eighteenth century, the engineer Amédée François Frézier joined the architectural speculation on the walkable extrados and described the design proposals by Abeille and Truchet in his Traité de Stéréotomie (1737). Like Truchet, 
Frézier also produces a series of alternative module designs. The first proposal (Fig. 4c) includes conical surfaces, while the following iterations make use of planes only (Fig. 4d-h).

In the nineteenth century, the Italian architect and engineer Lucio del Valle undertook the construction of two flat vaults for the site of the Canal de Isabel II, using one of the design solutions proposed by Frézier. Only one of the two vaults still exists and can be found in the dam of the Pontón de la Oliva.

The first Spanish example of Abeille's vault can be seen in the cathedral of Lugo, designed by the engineer Julián Sánchez Bort in 1769. In this instance, Bort suggested an innovative idea: inverting the flat vault in order to obtain a flat extrados and an aesthetically pleasing soffit featuring pyramidal voids.

Further to inverting the vault, Bort also introduces changes to the shape of the stone pieces: the original module geometry proposed by Abeille is adopted only on the perimeter, while the blocks toward the centre of the vault have a rectangular shape and a negative pyramidal intrados for visual purpose only (Moreno Gata et al. 2019).

\section{Topological Interlocking Materials (TIM)}

Following the historical debate prompted by Abeille's work, the research into the benefits of structural fragmentation has recently become popular again in the architecture and engineering fields. Abeille's proposal of combining simple geometric modules into more complex systems recalls the morphological principles behind the natural structure of many living organisms and can be linked to the engineering design concept of TIM.

The first assembly of polyhedra in recent history is Michael Glickman's invention of the G-Block system (1984) (Fig. 5a). This is the first modern structure using interlocking truncated tetrahedra. Looking at Fig. 5c, it is possible to appreciate the similarity between the G-block module and the module designed by Abeille. Perhaps inadvertently, the same interlocking principle has gained momentum in contemporary engineering.

In order to better understand the features of TIM systems, consider a speculative structure composed of interlocking tetrahedra. The regular tetrahedron (Fig. 5b) is a Platonic solid composed of four equilateral triangular faces. Many regular tetrahedra can be assembled together as shown in Fig. 6.

Given a plane of truncation that is parallel to the plane of tessellation of the tetrahedra: (1) if the plane of truncation intersects the midplane of the structure, the resulting intersection polygons will be squares; (2) if the plane of truncation is moved vertically, either upwards or downwards, the resulting intersection polygons will be rectangles; (3) the more the plane of truncation moves away from the midplane of the structure, the more elongated the intersection polygons, to a point where the rectangular polygons degenerate into segments (corresponding to the upper or lower edges of the tetrahedra) (Fig. 7) (Dyskin et al. 2003b).

Using the same interlocking principle, it is possible to generate assemblies of other Platonic solids, such as cubes, octahedra and dodecahedra (Dyskin et al. 


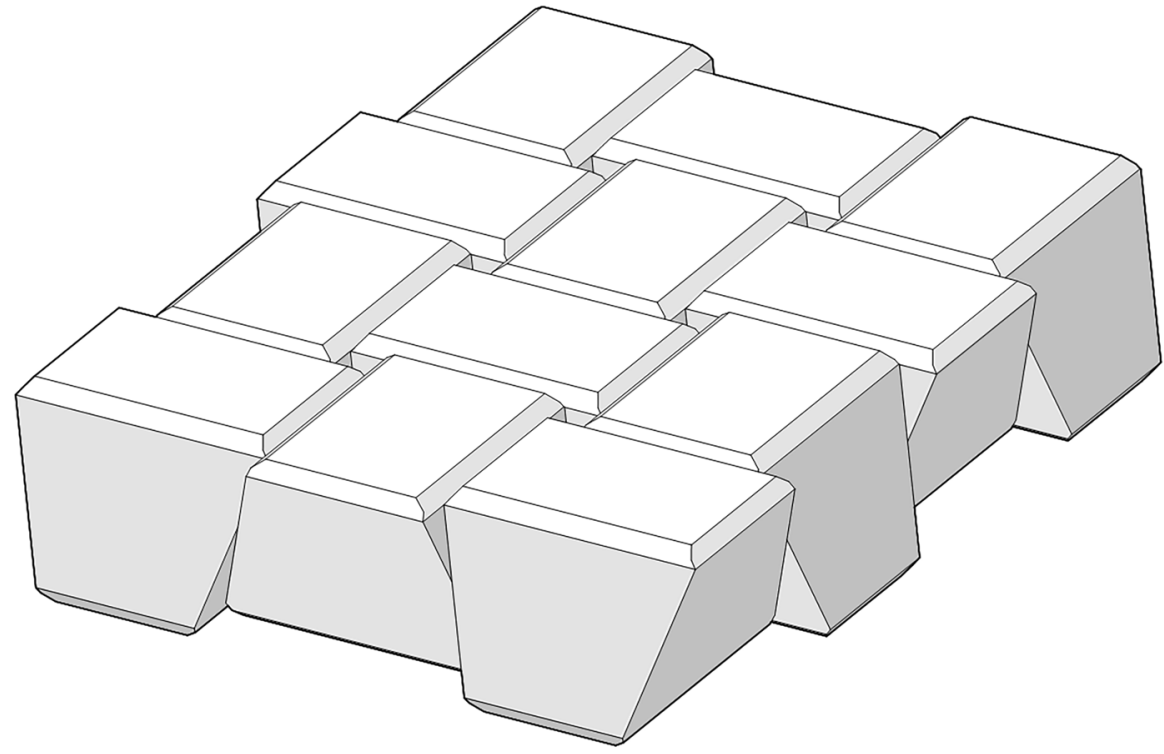

(a)

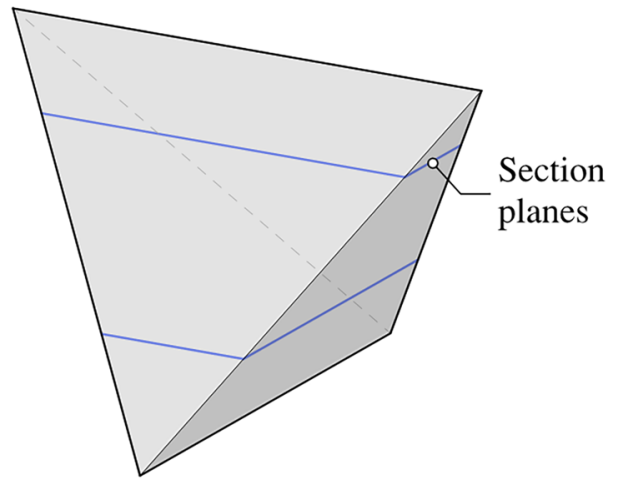

(b)

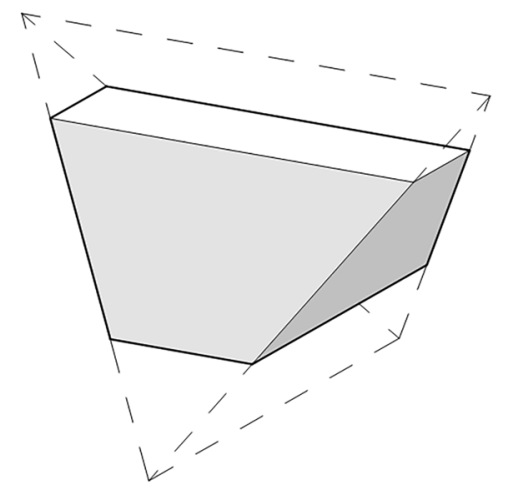

(c)

Fig. 5 a Interlocking principle of the G-Block system; b regular tetrahedron including truncation planes outlines; $\mathbf{c}$ the G-Block solid within the tetrahedron. Image: Authors, after Glickman (1984)

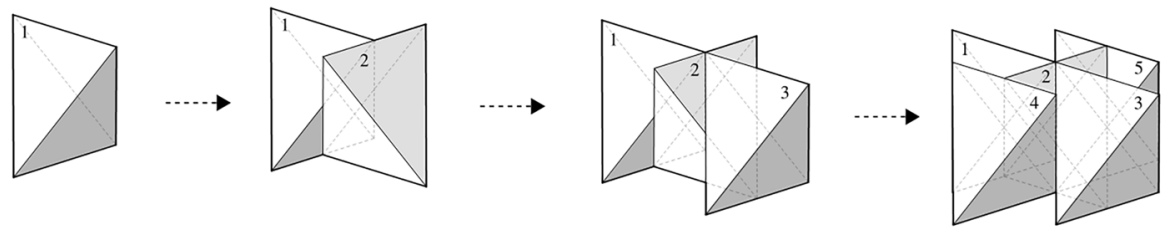

Fig. 6 Sequential assembly of unit elements to create topologically interlocking tetrahedra. Image: Authors, after Khandelwal et al. (2012) 


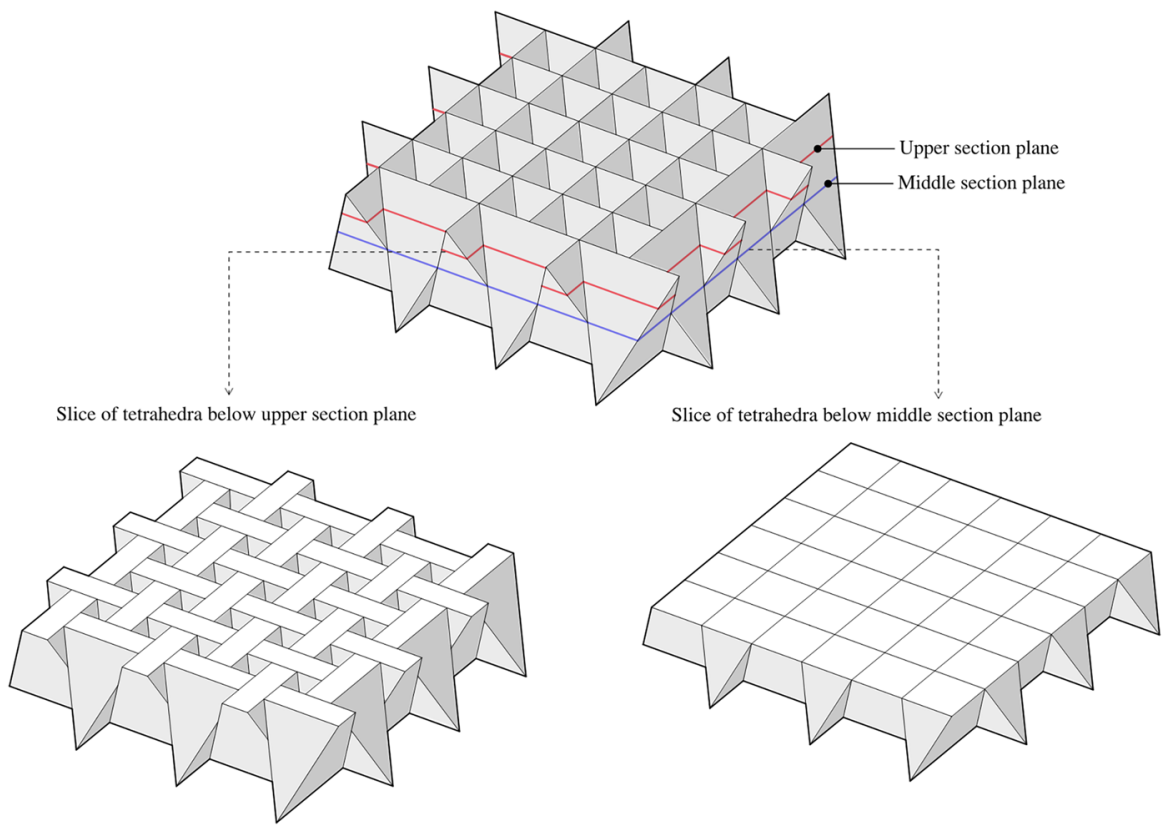

Fig. 7 Topological interlocking in a structure composed of tetrahedra: overview of the assembly and geometrical constructions based on displacement of the middle section. Image: Francesca Lecci

2001). These solids have a common feature: it is possible to tessellate them to obtain hexagonal intersection polygons in the midplane of the structure (Fig. 8). In this instance, the interlocking strategy entails that each module has six faces adjoining the adjacent modules, three of which prevent the module from moving vertically upwards, while the remaining three prevent the vertical movement in the opposite direction (Dyskin et al. 2003a).

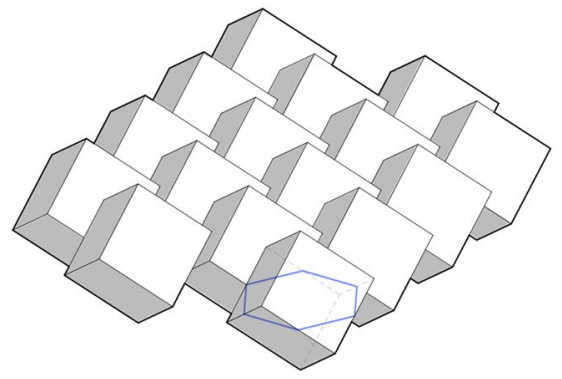

(a)

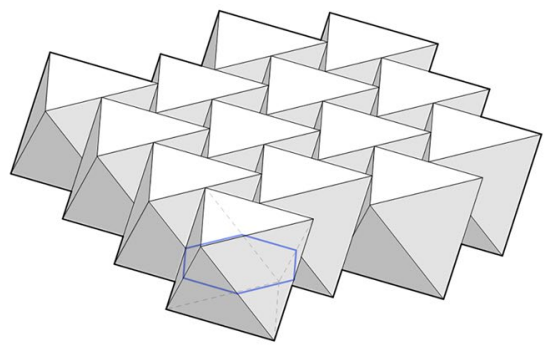

(b)

Fig. 8 Fragments of assemblies of interlocked cubes (a) and octahedra (b). A regular hexagonal middle section is shown for a corner element. Image: Authors, after Dyskin et al. (2003b) 
The fragmented nature of interlocking structures offers many advantages. First, it is possible to combine elements of different materials, also allowing the construction of hybrid structures. Furthermore, the fragmentation enhances the structural stability of the system, since the strength of a body made of a fragile material is inversely proportional to its size. In fact, the greater the size of an object, the higher the probability that it may contain critical defects that could potentially lead to failure. Another positive aspect of interlocking structures is the presence of intermediate interface surfaces that act as barriers to the propagation of cracks. The overall behaviour of the interlocking system in conditions of partial integrity is a particular feature: it has been demonstrated that, even in the absence of a certain percentage of its constituent parts (up to 25\%), interlocking systems are still able to play their structural role (Estrin et al. 2011). The fragmentation of the structure also implies an advantage in terms of energy dissipation: since the blocks are allowed a certain degree of movement (within the limits imposed by the kinematic constraints of the interlocking system), any vibrations of large amplitude can be dampened (which is a desirable quality in seismic regions). However, this type of structure is characterised by low bending stiffness, which can lead to structural problems (Estrin et al. 2004).

\section{Flat Vault Composed of Interlocking Cubes}

\section{Concept Design}

Among the five Platonic solids that may be used to generate TIM systems, the one adopted for the structure presented in this paper is the cube, given the simplicity of its manufacture from large blocks of stone or other massive structural material. In line with the approach previously used to explore the interlocking systems through progressive sections, the assembly of TIM cubes can also be better understood through the study of the trend of the cross-sections from one extreme vertex to the other. To fully understand the origin of the morphogenetic and constructive process of the proposed system, it is necessary to start from the analysis of the basic element. Take a section through a cube at an inclined plane, passing through its centre and the midpoints of its edges: this way it is possible to obtain a regular hexagonal section (Fig. 9).

Due to the substantial density of stone, it was decided to lighten the structure by removing the material above its mid-plane. As discussed, the section through the midplane of an interlocking structure composed of cubes generates a honeycomb pattern, while usefully providing a flat, walkable extrados (Fig. 10).

In order to overcome the low bending stiffness that characterises interlocking structures, it was also decided to provide mortar joints between the interlocking units: a new design feature is therefore introduced to the classic concept of the interlocking structure, which generally does not entail the use of connecting devices between the blocks (Khandelwal et al. 2014). This interlocking principle has been adopted to design a flat vault structure of $10 \times 10$ modules, as shown in Fig. 11 . 

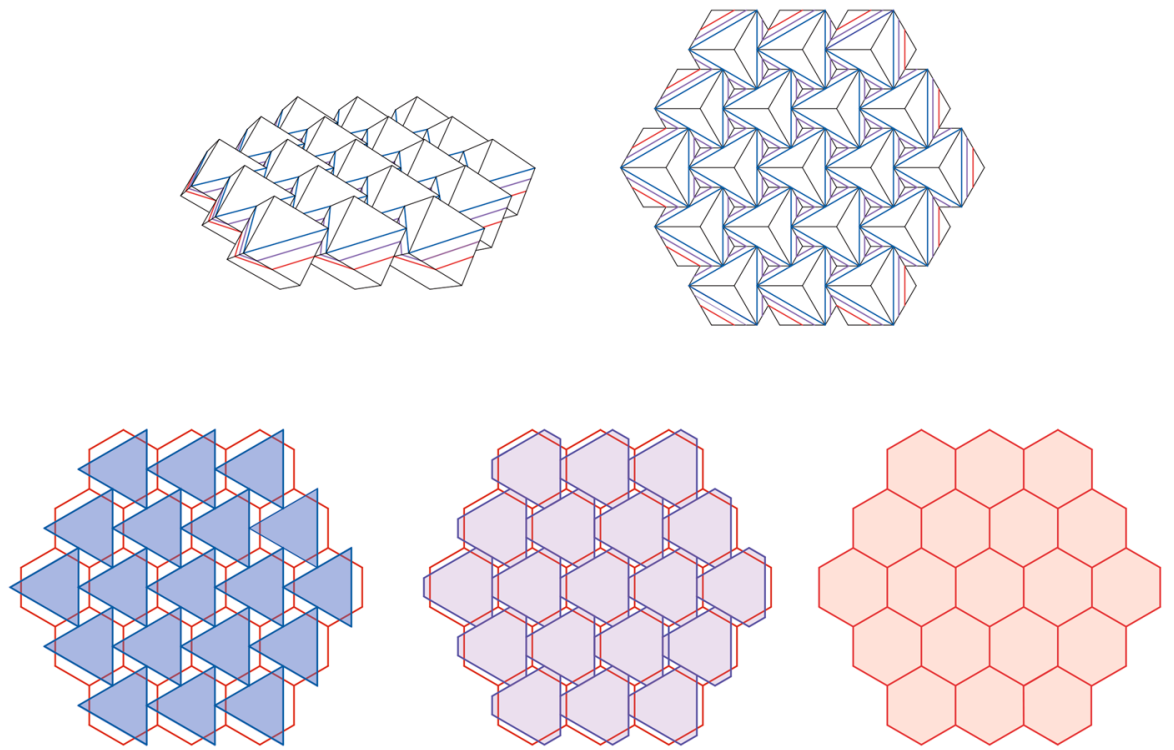

Fig. 9 Analysis of the progressive evolution of the section of the TIM interlocking system, consisting of cubes, along the direction perpendicular to the plane containing the flat vault. Image: Cecilia Mazzoli
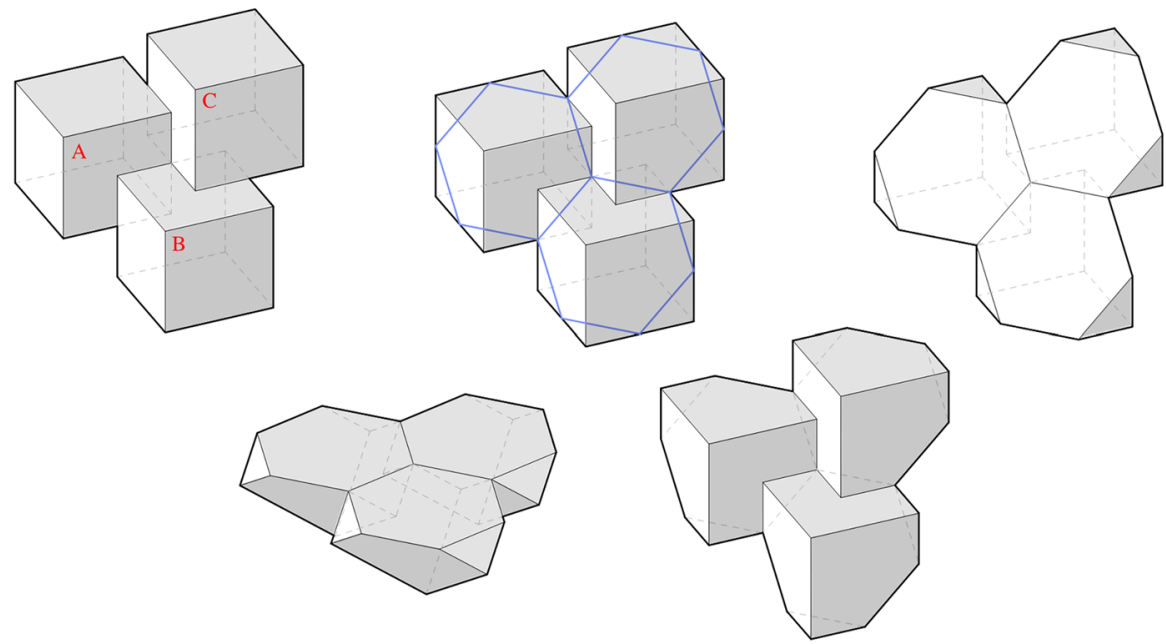

Fig. 10 Exemplification of the procedure to obtain the modules for the flat vault. Image: Francesca Lecci

\section{Analysis}

The structural performance of the proposed flat vault has been analysed through the Finite Element Method (FEM) in order to validate its design principles. The 

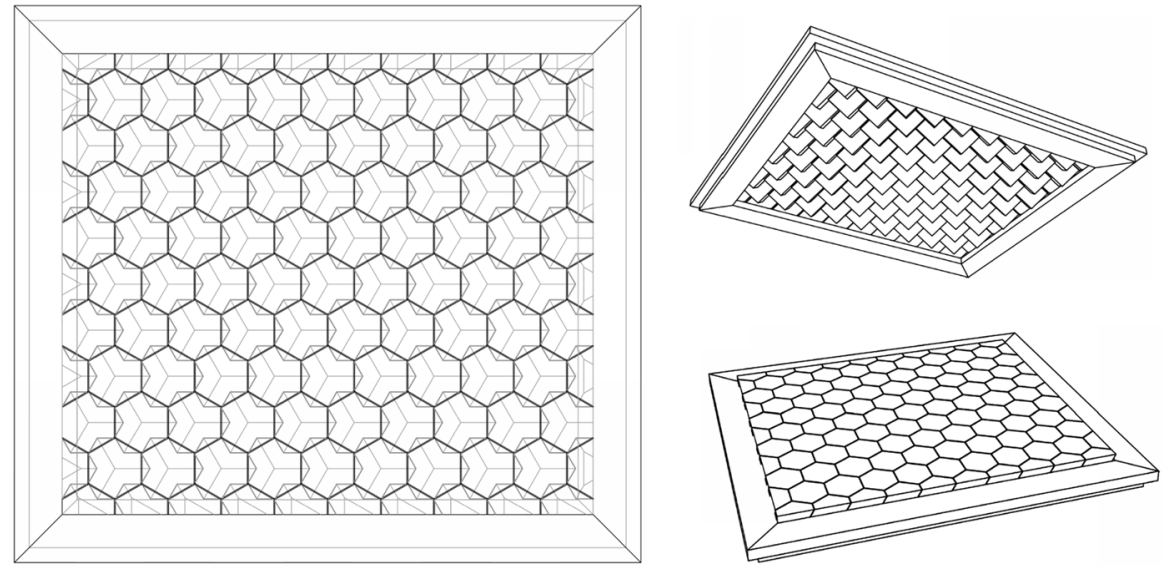

Fig. 11 TIM system composed of interlocking elements derived from cubic modules. a (left) Plan view; b (right) axonometric views. Image: Lecci (2013)

tool adopted for this assessment is Cast $3 \mathrm{M} 2000^{\circledR}$, a finite element software for structural and fluid mechanics developed by the French Commission for the Atomic Energy (Commissariat à l'Energie Atomique, CEA), which presented the opportunity of employing programming procedures for the modeling of stereotomic construction systems provided by the Joint Research Center (JRC) of the European Commission (Pegon et al. 2001; Pegon 1999).

The type of analysis carried out within the Cast $3 \mathrm{M} 2000^{\circledR}$ framework is heavily reliant on the precision of its numerical inputs. Using the software Wolfram Mathematica ${ }^{\circledR}$, it was possible to model the geometry of the various modules used for the composition of the floor structure and export the coordinates of their vertices with a controlled degree of approximation.

The proposed flat vault, although composed of elements with a precise and codifiable geometric shape, presents a considerable degree of complexity at a global level. The definition of the global geometry began with the creation of the basic component of the vault, that is, the module composed of cubes A, B and C that can be seen in Fig. 10. By reproducing these modules along several assembly rows and columns, an overall rhomboidal geometric structure was obtained. By carrying out three-dimensional rotation operations and isolating the modules lying on the area affected by the development of the slab, it was possible to obtain a floor structure (sides 2.50 and $2.17 \mathrm{~m}$ ) generated by cubes. By cutting the structure obtained with a plane passing through the mid-point of the edges of the cubes, it was possible to obtain the hexagonal tessellation that will constitute the extrados of the floor (Fig. 12). In the final phase of scripting in Wolfram Mathematica ${ }^{\circledR}$, the coordinates of the vertices of the units were exported with an adequate approximation to characterize the input data of Cast3M 2000 ${ }^{\circledR}$ (Le Fichoux 1998). This is the starting point for the modelling phase of the flat vault using the FEM.

After the creation of the geometry aimed at determining the coordinates of the vertices of the modules, these values were imported into the FEM calculation code. 

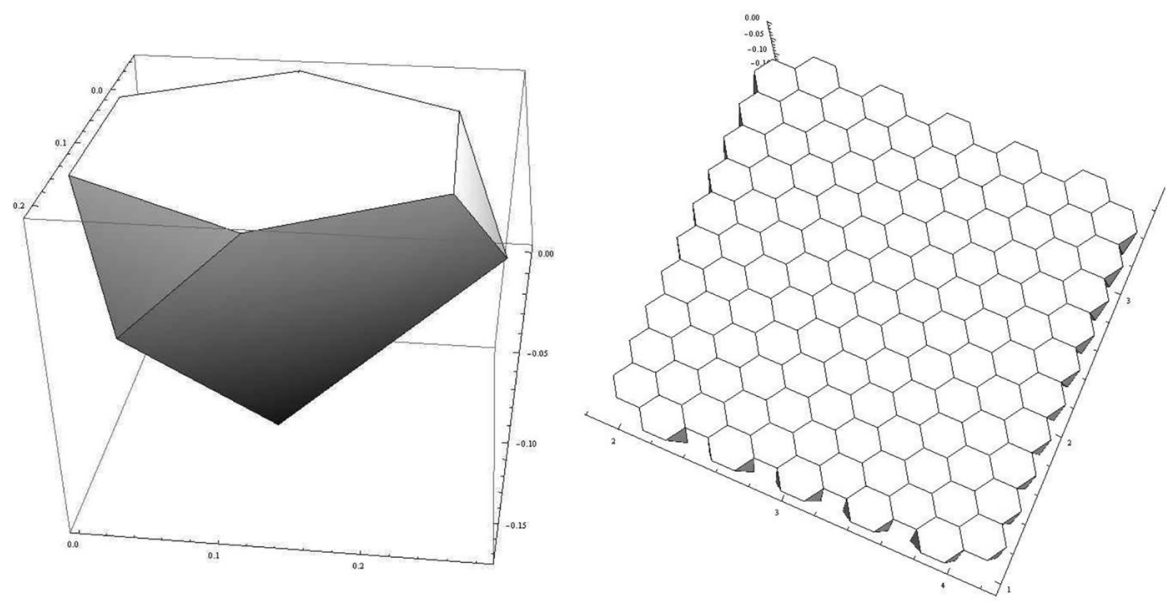

Fig. 12 Module geometry (left) and flat vault geometry (right) created with Wolfram Mathematica ${ }^{\circledR}$. Image: Lecci (2013)

From these three-dimensional geometrical coordinates, the meshes of the outer surfaces of the cubic blocks and their volume were created. Figure 13 shows the polygons and vertices used to create the surfaces in the Cast $3 \mathrm{M} 2000^{\circledR}$ environment (Fig. 14).

Following the creation of the geometry, the external constraints were defined: the movements of the perimeter ashlars were blocked, while allowing free rotation. These pinned restraint conditions were considered the best representation of the perimeter framework constraint, which, by exerting suitable pressure from the outside, prevents the peripheral segments from moving. Regarding load application, only the dead load of the structure was considered. The vertical displacements of the structure and Von Mises stress within the ashlars resulting from the analysis are shown in Fig. 15.

\section{Prototyping}

Following the phases of design and analysis of a flat vault composed of interlocking elements derived from cubic modules, a physical scale model (sides 35 and $39 \mathrm{~cm}$ ) was produced. Timber was chosen as the material for the physical prototype, as it allows a relatively easy process of fabrication of cubic modules starting from timber battens.

The first step of the process required the segmentation of the timber battens into cubes of the same dimensions (side $4 \mathrm{~cm}$ ). Thereupon, a hexagonal polygonal line joining the midpoints of the cube's edges was drawn on the modules. In order to cut the cubic modules, it was necessary to create a bespoke cutting jig that would allow support of the cubes during the cutting process (Fig. 16a). This allowed the cubes to be cut using a standard bandsaw (Fig. 16b). In order to account for the thickness of the bandsaw, the cutting plane of the module was shifted slightly from 


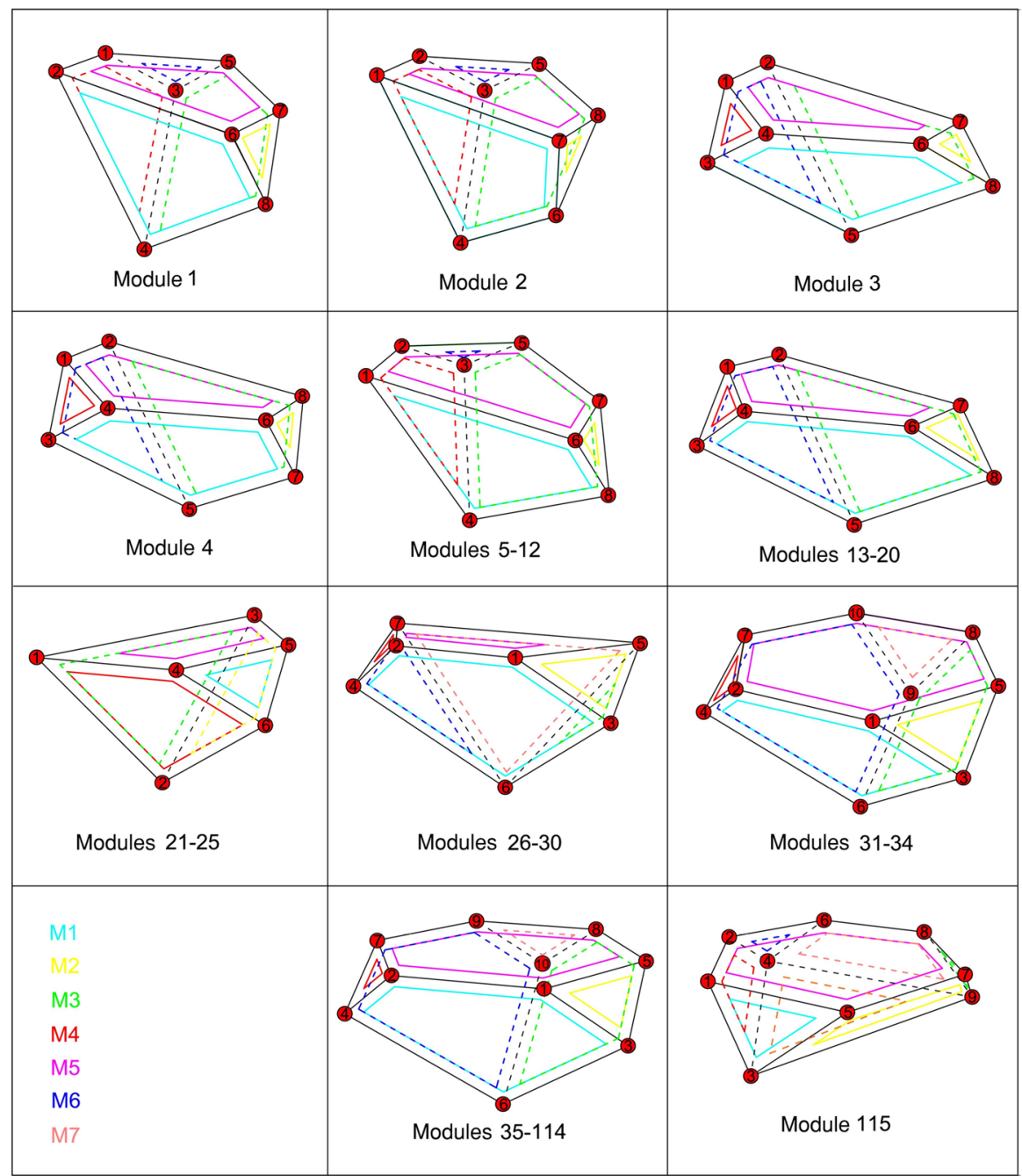

Fig. 13 Diagrams of the polygons built in order to create the external surfaces and volumes of the modules. Image: Lecci (2013)

the mid-plane polygonal line traced on the cubes. This approach made it possible to produce two complementary components of different sizes. The component having the smallest depth (module "B" in Fig. 16c) presented a surface deviating from a regular hexagonal shape, hence it was discarded. The remaining component (module "A") was sanded along its cutting plane to reduce local deviations and achieve a smooth appearance.

Following the manufacturing of the units, these were assembled with the extrados against a horizontal working table, as shown in Fig. 16d. For simplicity and costeffectiveness of construction, a wooden perimeter frame made of bespoke segments 


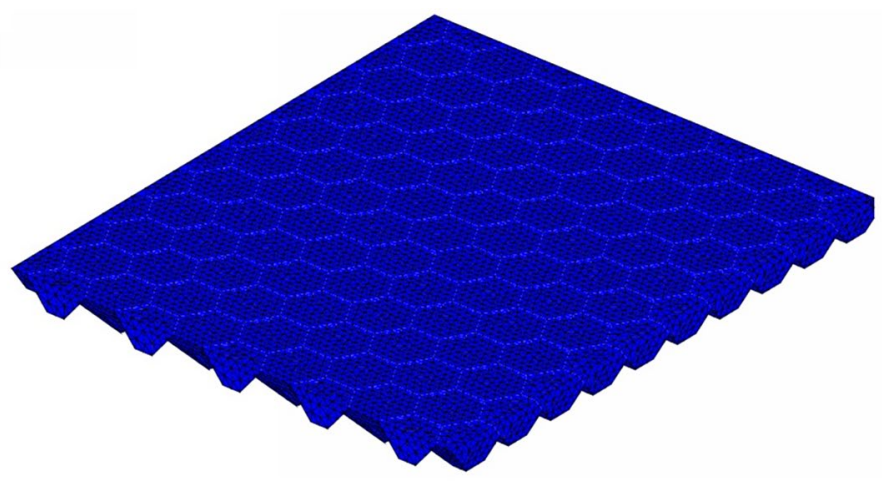

(a)

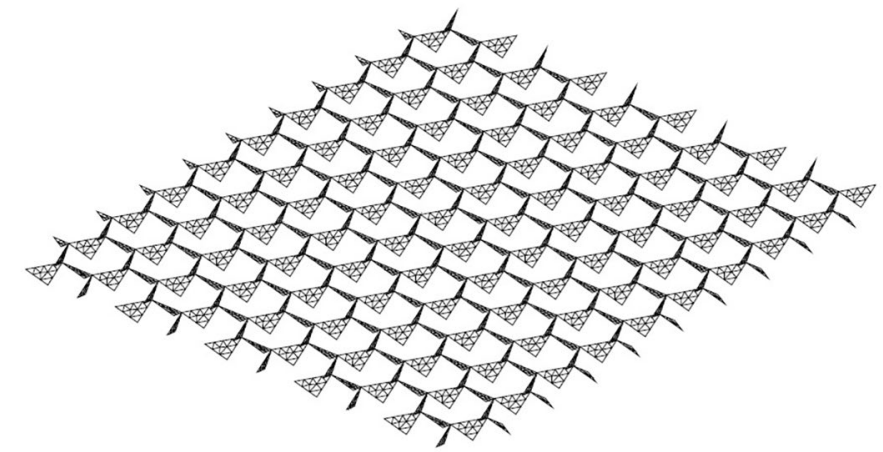

(b)

Fig. 14 a Meshes of the blocks created in Cast 3 M 2000 ${ }^{\circledR}$; b meshes of the joints created in Cast $3 \mathrm{M}$ $2000^{\circledR}$. Image: Lecci (2013)
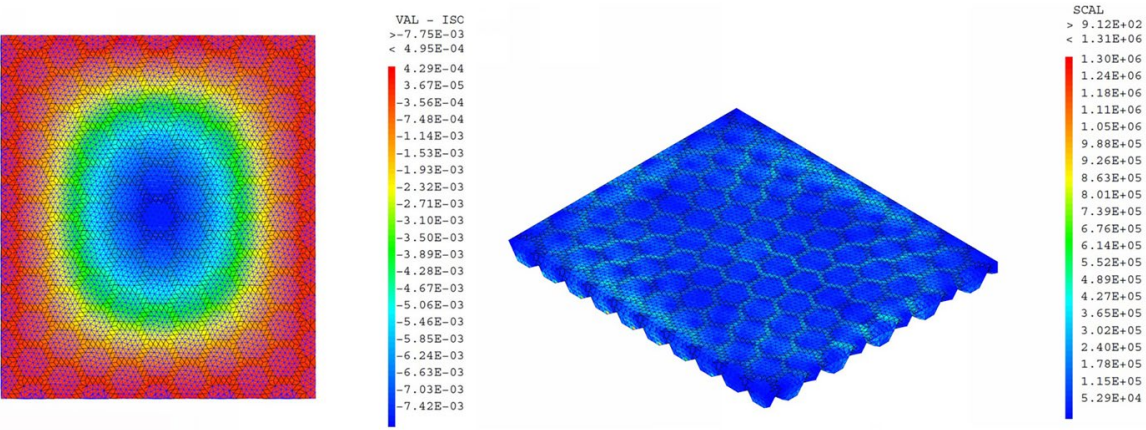

Fig. 15 Left: vertical displacement of the ashlars in metres (view from top). Right: Von Mises stress distribution within the ashlars (axonometric view) in Pa. Image: Lecci (2013) 

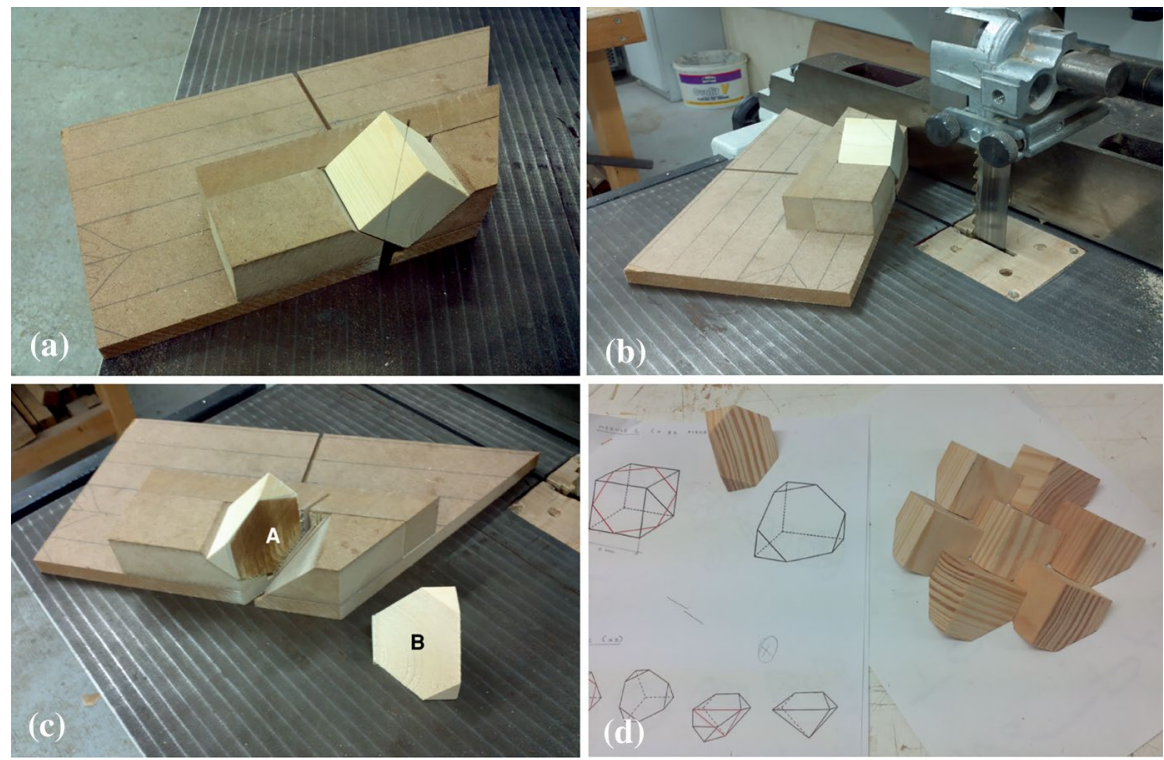

Fig. 16 a Jig to support cubic modules during cutting; b bandsaw used to cut timber modules; c complementary parts of cubes resulting from cutting process; $\mathbf{d}$ modules assembly. Images: Lecci (2013)

of timber battens with $45^{\circ}$ joints was designed as a support and confinement element. In order to allow the tightening of the frame around the interlocking timber modules, the battens were provided with pilot bolt holes at corner locations (Fig. 17a). Once all the modules were assembled together, the external frame was installed around the tessellated structure leaving a clearance at joint locations between the battens to allow the adjustment of their relative position. The frame was subsequently tightened with bolts (Fig. 17b) in order to apply compression on the various modular elements and lock them into position (Fig. 17c, d).

Because timber is a light-weight material, the physical prototype was not subjected to the same shear loads characterising equivalent stone structures, hence it was possible to achieve the structural integrity of the model without the use of glue between the modules, relying solely on the compression mechanism between the parts.

The resulting physical prototype was subjected to a concentrated load of $45 \mathrm{~N}$ (Fig. 18) in order to verify its mechanical behaviour. It has been demonstrated that the structure could withstand the vertical load and transfer it to the surrounding timber frame, thanks to its state of pre-compression given by the external constraint.

\section{Architectural and Aesthetic Values}

From an architectural point of view, the system has considerable advantages in terms of prefabrication of the modules, as they are identical to each other (Loing et al. 

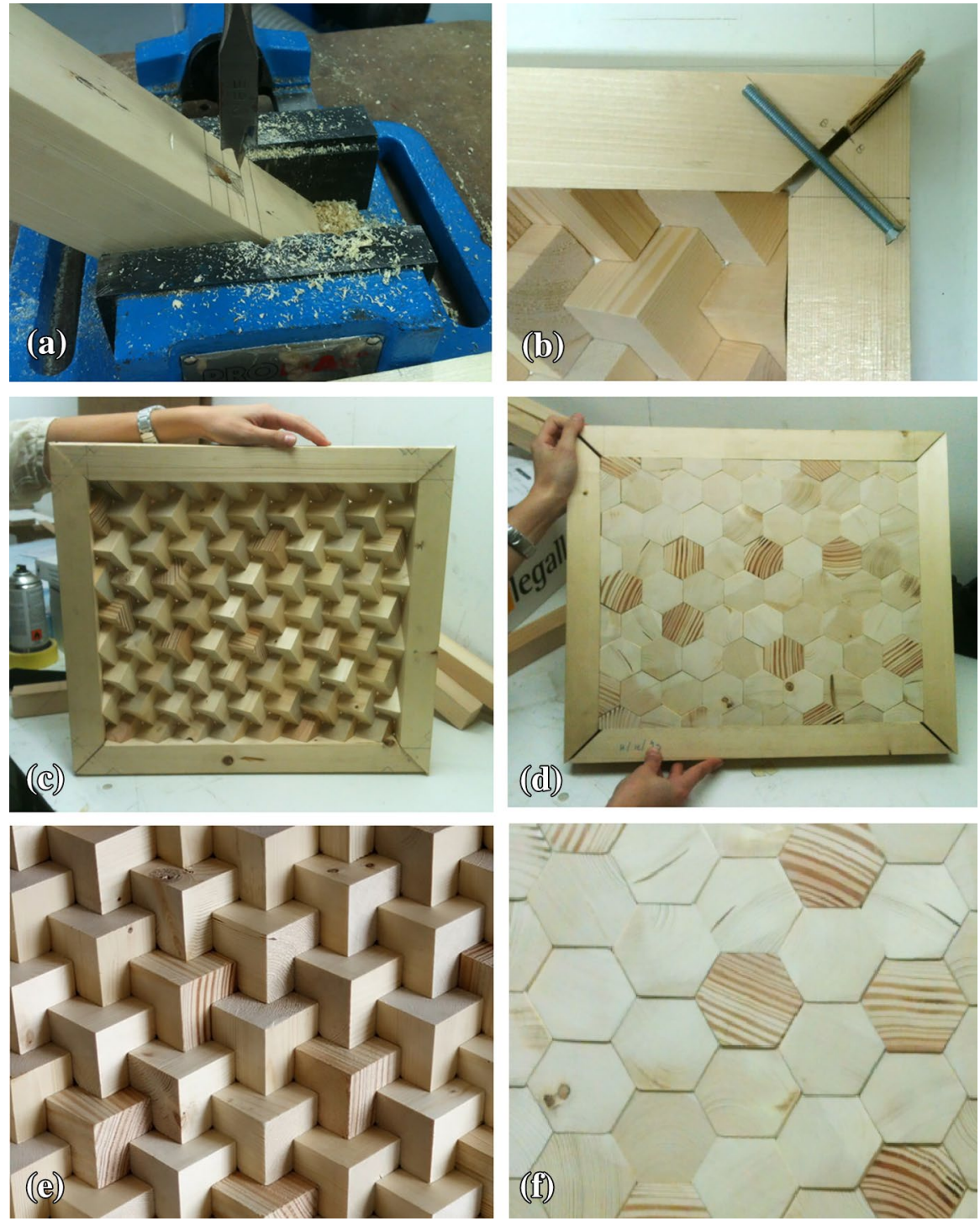

Fig. 17 a Drilling of bolt holes at $45^{\circ}$ to timber frame edges; $\mathbf{b}$ bolt type used to tighten frame at corner locations; c view of peripheral timber frame and intrados of TIM structure; $\mathbf{d}$ view of peripheral timber frame and extrados of TIM structure; e detail of the intrados of the physical prototype of the TIM structure; $\mathbf{f}$ detail of the extrados of the physical prototype of the TIM structure. Images: Lecci (2013)

2020). The components can therefore be easily made using different fabrication processes in addition to the one presented in this paper: depending on the material used, 3D printing, cutting with $\mathrm{CNC}$ machines and casting inside moulds could be used. 

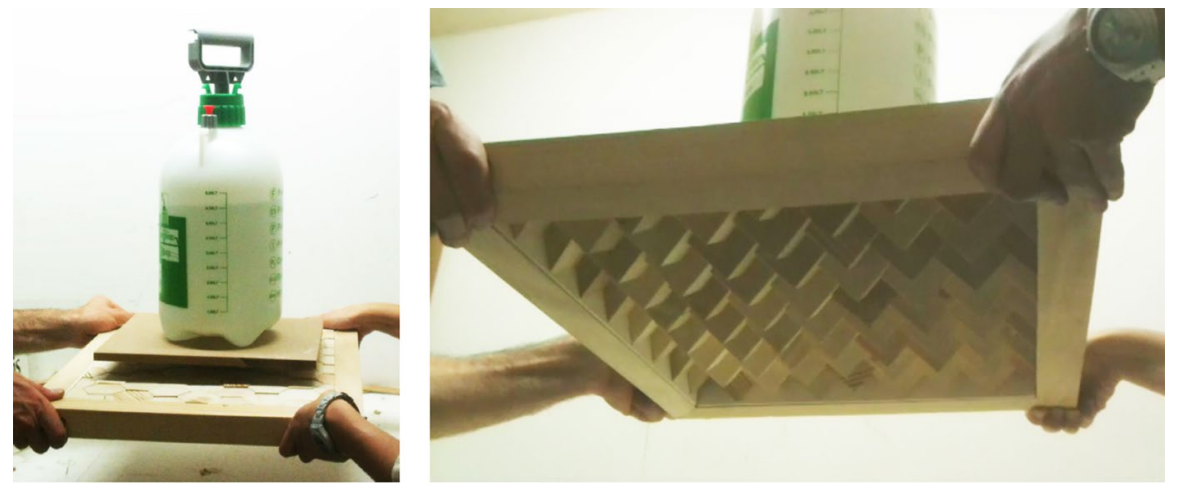

Fig. 18 Loading test of TIM system prototype. Image: Lecci (2013)

From an aesthetic and geometric point of view, the resulting intrados design of the flat vault is extremely interesting, as it features light and shadow motifs resulting from the edges of the solids sloped at precise angles.

Through the prototyping experience it was also possible to observe an aesthetic feature deriving from the occurrence of fabrication and assembly tolerances: due to small deviations of the edges of the fabricated modules from the nominal dimensions, the overall TIM structure presents repeating voids at the vertexes of the hexagonal extrados tiles. Due to this feature, when the TIM system prototype is backlit, it creates pleasing light patterns, as shown in Fig. 19.

\section{Applications of the Model}

The same model employed for the flat vault could be implemented through the same methodological approach for the construction of vertical building elements, such as load-bearing partitions or prefabricated cladding panels (Mazzoli 2015).

Similarly to the flat vault system, the solidity of a façade panel consisting of TIM cubes is guaranteed by the presence of a hexagonal tiling of the median planein this case vertical, and not horizontal-combined with a perimeter confinement element to allow the transmission of reciprocal compression forces between cubes. As an alternative to the perimeter frame of the panel, it is possible to insert steel tierod cables inside the cubes, in alternate rows, which also act as an anchorage system for the panel to a structural kerb at the top of the tessellated structure.

By sectioning the panel according to vertical planes placed at different depths with respect to the hexagonal median section, the TIM cube system makes it possible to obtain a pattern of the façade with irregular hexagonal and triangular cells. In addition to having a suggestive chiaroscuro effect, this texture allows local variations of the thickness and, therefore, the thermal resistance of the façade system. The only fundamental requirement to be considered is the need to not exceed the vertical median section of each cube, which guarantees the complete tessellation of the space and ensures the mechanical functioning of the interlocking structure. 

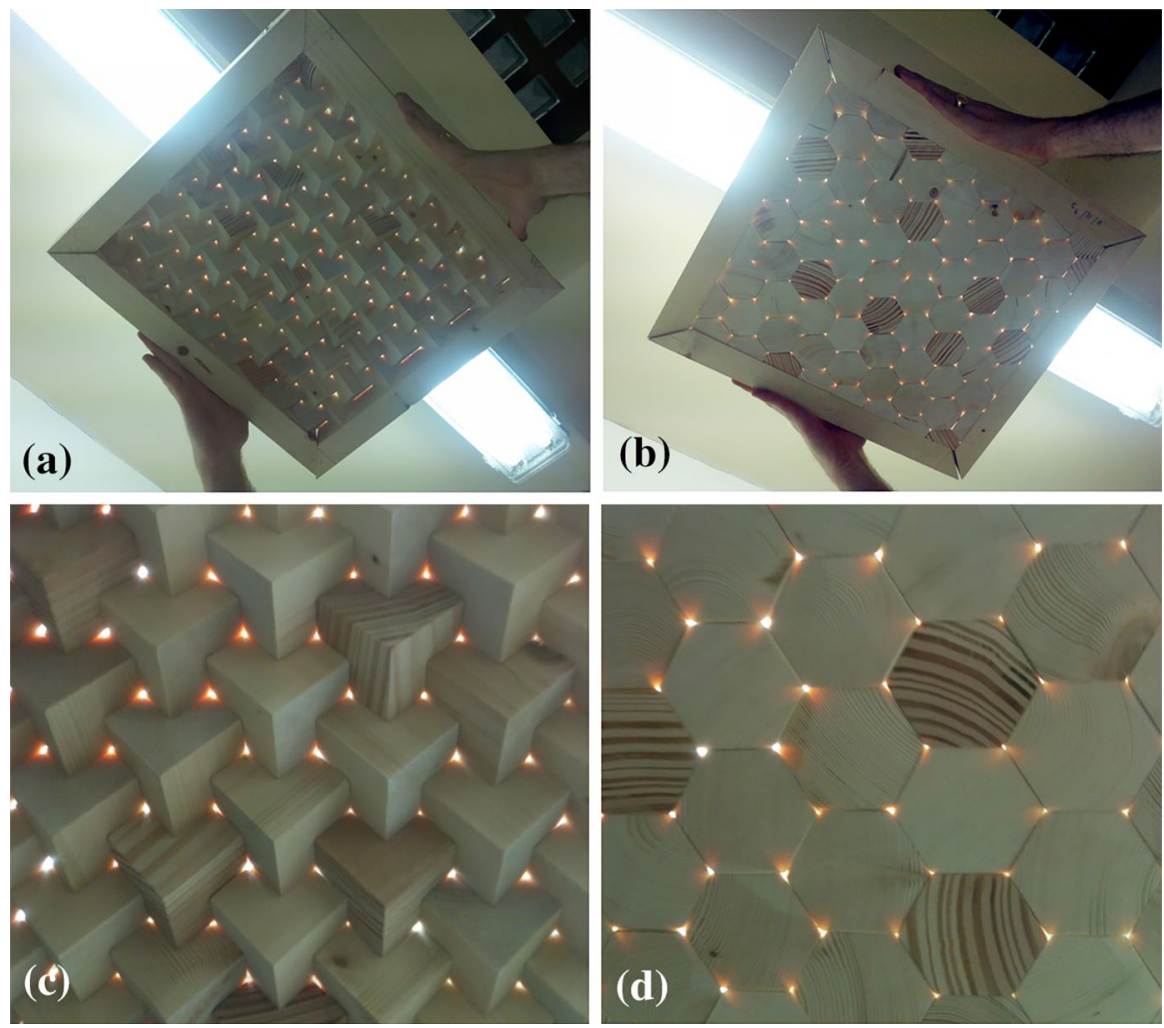

Fig. 19 a View of intrados of TIM structure against light; $\mathbf{b}$ view of extrados of TIM structure against light; $\mathbf{c}$ detail of the intrados of the physical prototype of the TIM structure against light; $\mathbf{d}$ detail of the extrados of the physical prototype of the TIM structure against light. Image: Lecci (2013)

As shown in Fig. 20, the formal possibilities that can be achieved by designing TIM systems are numerous and lead to the development of highly decorative geometries in the field of product design and architectural design (Piekarski 2018). Through this façade system, it is therefore expected to be able to meet both the architectural and performance requirements of the building envelope.

\section{Conclusions}

This paper presents the study of an innovative flat vault system composed of TIM cubes. The system has been analysed and designed according to the geometrical and constructive criteria typical of TIM systems, with the aim of combining mechanical performance requirements with aesthetic architectural qualities.

The FEM analysis conducted on the proposed flat vault suggests that this type of structure, when constructed with stone blocks and mortar joints, can achieve vertical deflections in the region of $1 / 290$ of the structural span. This result is 

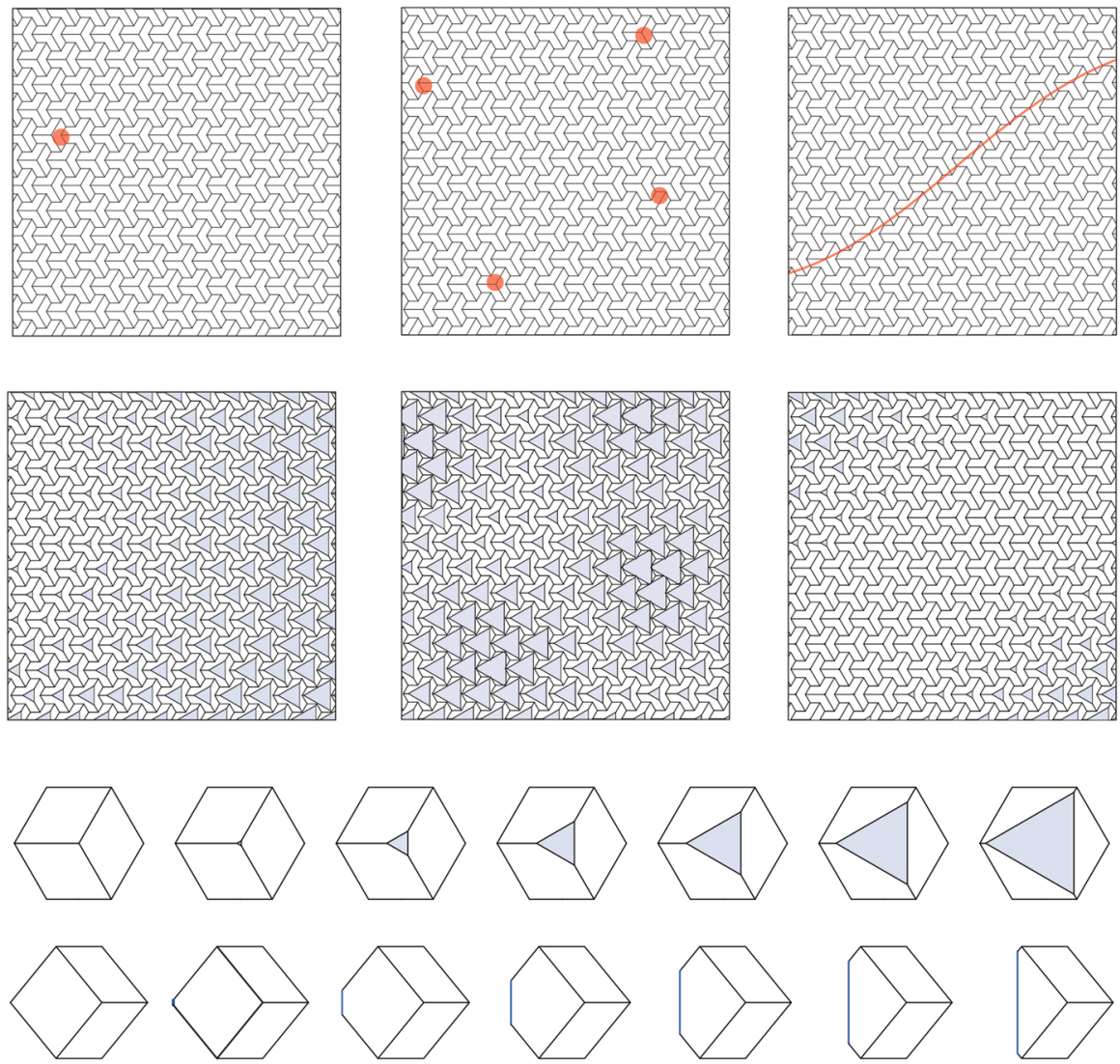

0

$x$

$2 X$

$3 x$

$4 \mathrm{X}$

$5 X$

$6 \mathrm{X}=\max$

Fig. 20 Exploration of the formal possibilities obtainable from the sectioning of the cubes constituting the façade panels, along vertical planes placed at a distance from the external vertex variable according to the algorithms defined by the user, through the use of parametric design software. Image: Cecilia Mazzoli

valid for stone structures subjected to dead load only and if no peripheral movement is allowed.

Through the testing of the physical prototype it has been demonstrated that, when made of a lighter material such as timber, the proposed TIM structure can also withstand substantial concentrated loads without losing its structural integrity. It is particularly interesting that the tested prototype did not entail the use of glue between the modules, proving that this flat vault can be assembled as a dry system, provided that the peripheral constraints are able to counteract the applied loads through a compression mechanism.

Using a dry system would also present environmental advantages, since it makes it possible to disassemble the structure and re-use or recycle the original material as uncontaminated. 
Physical prototyping of the designed TIM structure made of stone material could provide a validation for the results obtained through the FEM analysis. This is not part of the current research and could represent a further development of this study.

Acknowledgements The research project was carried out as part of Francesca Lecci's master's degree Thesis in Building Engineering-Architecture at the University of Bologna, under the direction of Prof. Riccardo Gulli. In particular, the thesis was carried out in collaboration with the Laboratoire GSA of the École Nationale Supérieure d'Architecture (ETSA) de Paris-Malaquais, in co-direction with Prof. Maurizio Brocato and was supported by the scholarship "Borsa di studio per periodi di ricerca all'estero per la preparazione e l'approfondimento della tesi di laurea specialistica, magistrale o a ciclo unico" granted by the University of Bologna. The study is part of the morphological and structural research conducted by both the Laboratoire GSA of Paris and the Department of Architecture of the University of Bologna, within which Cecilia Mazzoli's PhD thesis was also developed, carried out in collaboration between the two universities. The development of the PhD thesis was supported by "Contributo di mobilità per tesi di Dottorato in cotutela" granted by Université Franco-Italienne.

Funding Open access funding provided by Alma Mater Studiorum - Università di Bologna within the CRUI-CARE Agreement.

Open Access This article is licensed under a Creative Commons Attribution 4.0 International License, which permits use, sharing, adaptation, distribution and reproduction in any medium or format, as long as you give appropriate credit to the original author(s) and the source, provide a link to the Creative Commons licence, and indicate if changes were made. The images or other third party material in this article are included in the article's Creative Commons licence, unless indicated otherwise in a credit line to the material. If material is not included in the article's Creative Commons licence and your intended use is not permitted by statutory regulation or exceeds the permitted use, you will need to obtain permission directly from the copyright holder. To view a copy of this licence, visit http://creativeco mmons.org/licenses/by/4.0/.

\section{References}

Abeille, J., Mémoire concernant la voûte plate inventée par M. Abeille. 1699. Gallon J-G., Académie royale des Sciences, Machines et inventions approuvées par l'Académie Royale des Sciences depuis son établissement jusqu’à present; avec leur Description. Dessinées \& publiées du consentement de l'Académie, Tome 1, 1735.

Dyskin, A.V., Y. Estrin, A.J. Kanel-Belov, and E. Pasternak. 2001. A new concept in design of materials and structures: assemblies of interlocked tetrahedron-shaped elements. Scripta Materialia 44(12): 2689-2694.

Dyskin, A.V., Y. Estrin, A.J. Kanel-Belov, and E. Pasternak. 2003a. A new principle in design of composite materials: reinforcement by interlocked elements. Composites Science and Technology 63: 483-491.

Dyskin, A.V., Y. Estrin, A.J. Kanel-Belov, and E. Pasternak. 2003b. Topological Interlocking of Platonic Solids: A Way to New Materials and Structures. Philosophical Magazine Letters 83(3): 197-203.

Estrin, Y., A.V. Dyskin, and E. Pasternak. 2011. Topological interlocking as a material design concept. Materials Science and Engineering C 31: 1189-1194.

Estrin, Y., A.V. Dyskin, S. Schaare, S. Stanchits, and A.J. Kanel-Belov. 2004. Negative stiffness of a layer with topologically interlocked elements. Scripta Materialia 50(2): 291-294.

Fallacara, G. 2007. Verso una progettazione stereotomica. Nozioni di stereotomia, stereotomia digitale e trasformazioni topologiche: ragionamenti intorno alla costruzione della forma. Roma: Aracne Editrice.

Frézier, A.-F. 1737. La théorie et la pratique de la coupe des pierres et des bois pour la construction des voutes et autres parties des bâtiments civils. Paris: Jean-Daniel Doulsseker Editeur. 
Glickman, M. 1984. The G-Block System of vertically interlocking paving. 2nd International Conference on Concrete Block Paving Proceedings. Delft (Netherlands): 345-348.

Khandelwal, S., T. Siegmund, R.J. Cipra, J.S. Bolton. 2012. Transverse loading of cellular topologically interlocked materials. International Journal of Solids and Structures 49(18): 2394-2403.

Khandelwal, S., T. Siegmund, R.J. Cipra, and S.J. Bolton. 2014. Scaling of the Elastic Behavior of TwoDimensional Topologically Interlocked Materials Under Transverse Loading. Journal of Applied Mechanics 81(3):031011.

Lecci, F. 2013. Trave armata in pietra da taglio: interpretazione, sperimentazione costruttiva ed innovazione di una tecnica della tradizione. Master Degree Thesis, University of Bologna, Tutor: Prof. Ing. R. Gulli, Co-tutor: Prof. Ing. M. Brocato, Prof. Ing. G. Mochi.

Le Fichoux, E. 1998. Presentation et utilisation de Castem 2000. ENSTA-LME. http://www-cast3m.cea. $\mathrm{fr} / \mathrm{html} / \mathrm{doc} /$ ManuelCastemEnsta.pdf (accessed 29 October 2020).

Loing, V., O. Baverel, J.-F. Caron, and R. Mesnil. 2020. Free-form structures from topologically interlocking masonries. Automation in Construction 113: 103117.

López Mozo, A. 2003. Planar vaults in the Monastery of El Escorial. Proceedings of the First International Congress on Construction History (Madrid, 20-24 January 2003), ed. S. Huerta, 13271334. Madrid: I. Juan de Herrera.

Mazzoli, C. 2015. Sistemi tecnologici innovativi di involucro per il recupero del patrimonio edilizio recente. L'edilizia scolastica nel Comune di Bologna/Systèmes technologiques de façade innovants pour la rénovation du patrimoine bâti contemporain. Le bâtiments scolaires à Bologne. $\mathrm{PhD}$ Thesis, University of Bologna - École Nationale Supérieure d'Architecture de Paris-Malaquais, Tutor in Italy: Prof. Ing. R. Gulli - Tutor in France: Prof. Ing. M. Brocato.

Moreno Gata, K., C. Mueller, and E. Echeverría Valiente. 2019. Designing strategies for Topological Interlocking Assemblies in architecture. Flat Vaults. Proceedings of the IASS Annual Symposium 2019 - Structural Membranes 2019 - Form and Force, Barcelona: 1-8.

Noël, P. 1994. Technologie de la pierre de taille. Dictionnaire des termes couramment employés dans l'extraction, l'emploi et la conservation de la pierre de taille. Paris: SEBTP.

Pegon, P. 1999. Automatic generation of blocks connected with joints. Technical Report. JRC-Special Publication, No. I.99.101, Joint Research Center (JRC).

Pegon, P., A. V. Pinto and M. Géradin. 2001. Numerical modelling of stone-block monumental structures. Computers and Structures 79: 2165-2181.

Piekarski, M. 2018. New Concepts for Application of Topological Interlocking In Architecture. eCAADe 2018 Proceedings of the $36^{\text {th }}$ International Conference on Education and Research in Computer Aided Architectural Design in Europe - Shape, Form \& Geometry I Applications, Łódź, Vol. 2, eCAADe and Faculty of Civil Engineering, Architecture and Environmental Engineering, Łódź University of Technology: 467-476.

Rabasa Díaz, E. 1998. La bóveda plana de Abeille en Lugo. Actas del Segundo Congreso Nacional de Historia de la Construcción, La Coruña. 22-24 octubre 1998, eds. F. Bores, J. Fernández, S. Huerta, E. Rabasa, 409-415. Madrid: I. Juan de Herrera.

Publisher's Note Springer Nature remains neutral with regard to jurisdictional claims in published maps and institutional affiliations.

Francesca Lecci Chartered Engineer and Architect, Senior Façade Engineer at Arup (London). She graduated in Building and Architectural Engineering at the University of Bologna and developed her master's degree dissertation at the Laboratoire GSA of the École Nationale Supérieure d'Architecture de Paris-Malaquais. As a Façade Consultant, Francesca has been involved in prestigious multi-disciplinary projects in Europe and Middle East, gaining extensive knowledge on technical design, materials properties and complex geometry applied to the building envelope. Francesca has also worked as researcher at the CWCT Centre for Window and Cladding Technology (Bath) and lecturer at the Façade Engineering MSc at the University of the West of England-Faculty of Environment and Technology (Bristol) on the subjects of building physics, glazing materials and facade systems.

Cecilia Mazzoli Fellow Researcher at the University of Bologna (UNIBO). Graduated in Building and Architectural Engineering at UNIBO and Ph.D. in Architecture at UNIBO in co-direction with the 
Université de Paris-Est, with a degree recognized in Italy and France. Her profile is oriented towards the enhancement of cultural heritage, the preservation of local constructive techniques, the conservation and restoration of historical and recent built patrimony, performance renovation and energy refurbishment of recent building stock. She publishes papers on the abovementioned research fields and presents them in national and international congresses. Since 2011 she collaborates with the Department of Architecture of UNIBO, participating in research EU projects and conducting teaching activities as Professor on contract and Tutor for Technical Architecture for the Degree in Building and Architectural Engineering and Advanced Design, and for Technical and Digital Design for the Degree in Civil Engineering.

Cristiana Bartolomei Associate Professor at the University of Bologna (UNIBO) and member of scientific board of Architecture Doctorate of Bologna. Graduated in Master's degree in Architectural Engineering at UNIBO and Ph.D. in "Built Heritage Survey and Representation". Master in "Architettura per lo Spettacolo" e in "Architectural heritage restoration" at University of Genova. She conducts research in various fields of architecture designing and projecting. These include innovative surveying technologies and techniques, modelling, methodologies of representation and informative systems developed for architecture. She has been author in main international conferences and winner of international prices in various architectural competitions. She is participant of national and international research projects (PRIN, H2020, FARB). She is author of about 120 national and international scientific publications and reviewer in many international journals.

Riccardo Gulli Full Professor and Deputy Rector to Buildings and Sustainability at the University of Bologna (UNIBO). His engagement in didactic and scientific activities regards the Engineering schools of the University of Ancona, Perugia, Udine. From 2005 he is Director of the Research Institute LabTeco (Laboratory of design and technological experimentation of building heritage), UNIBO; Director of Industrial Research Laboratory NEREA (Network for the Advanced Restoration of the Emilia-Romagna High Technology Network); from 2010 he was Scientific Responsible of CIRI BUILDING AND CONSTRUCTION, UNIBO. From 2011 he is Responsible of the Unit Department of Architecture of UNIBO; President of the Course Study in Building Architecture and Engineering of Alma Mater; Member of the Scientific Committee of International Congress on Construction History. His main fields of research and didactic are focused on the sectors of historical construction techniques, building refurbishment and architectural design. 